Research Article

\title{
Predictive Analysis for the Thermal Diffusion of the Plasma-Assisted Machining of Superalloy Inconel-718 Based on Exponential Smoothing
}

\author{
Chen Shao-Hsien ${ }^{1}{ }^{1}$ and Kun-Tan Tsai ${ }^{2}$ \\ ${ }^{1}$ The Graduate Institute of Precision Manufacturing, National Chin-Yi University of Technology, Tai-Chung, Taiwan \\ ${ }^{2}$ Department of Mechanical Engineering, National Chin-Yi University of Technology, Tai-Chung, Taiwan \\ Correspondence should be addressed to Chen Shao-Hsien; e6036@ncut.edu.tw
}

Received 6 September 2017; Revised 23 December 2017; Accepted 9 January 2018; Published 3 April 2018

Academic Editor: Shuo Yin

Copyright (c) 2018 Chen Shao-Hsien and Kun-Tan Tsai. This is an open access article distributed under the Creative Commons Attribution License, which permits unrestricted use, distribution, and reproduction in any medium, provided the original work is properly cited.

\begin{abstract}
Nickel base and titanium base materials have been widely applied to engines in aerospace industry, and these engines are essential components of airplanes. The machining characteristics of aerospace materials may cause machining cutters to be worn down in a short time and thus reduce the accuracy of processing. The plasma-assisted machining adopted in the research is a kind of the complex machining method. In the cases of nickel base and titanium base alloys, the method can heat workpieces in an extremely short duration to soften the materials for the ease of cutting so that the cutting force, cutter wear, and machining cost will all be reduced. The research adopted plasma heating to soften parts of the materials and aimed to explore the heating of nickel base alloy. The temperature variation of the materials was investigated and measured by adjusting the current and feed velocity. Moreover, Inconel-718 superalloy was adopted for the comparison with nickel base alloy for the observation of the influence and change brought by heat, and the method of exponential smoothing was adopted to conduct the prediction and analysis of thermal diffusion for understanding the influence and change brought by electric current on nickel base materials. Finally, given the current from $20 \mathrm{~A}$ to $80 \mathrm{~A}$ and feed velocity from $1,000 \mathrm{~mm} / \mathrm{min}$ to $3,000 \mathrm{~mm} / \mathrm{min}$, the influence of thermal diffusion was investigated and the related model was built.
\end{abstract}

\section{Introduction}

Today, high heat-resistant materials of high strength have been widely applied in aerospace industry and national defense industry. However, the materials with better mechanical properties are harder to be machined in general. It becomes a great challenge for modern industries which require higher surface accuracy of the workpiece, higher machining efficiency, and lower machining cost. One of the common issues is higher machining cost if some specific processes are adopted in production. Based on the concept of complex machining, one of the solutions is the integration of a plasma welding machine and a lathe machine (or a milling machine) [1]. Applying the heat source of plasmaassisted machining to soften materials first will create an extremely short heating duration before cutter reaches the workpiece. During the extremely short heating duration, the workpiece will absorb heat and soften its materials, leading to phase changes.

In recent years, foreign scholars investigate heat-assisted machining by exploring the machining characteristics with the use of various heat sources (such as laser and plasma). There are many related literatures. Shin [2] and other scholars compared the other technologies, which were traditional machining, laser machining, and plasma-assisted machining, by measuring the residual stress with an X-ray diffraction and analyzing the temperature distribution of heat conduction. Their experiments indicated that both laser-assisted machining and plasma-assisted machining provide great surface accuracy and removal rate for difficult-to-machine materials.

Lamikiz and Celaya [3] conducted a plasma-assisted milling experiment for Inconel-718. The results showed 
that the cutting force can be reduced by $25 \%$, the lifetime of the cutter can be extended by about $100 \%$, and the removal rate can be enhanced by $250 \%$. It indicated the importance and the significant difference caused by preheating with an additional heat source.

Anderson et al. [4] investigated the laser-assisted machining for Inconcel-718 and then analyzed the machining cost. The results showed that the cutting force can be reduced by $25 \%$, surface roughness can be $2-3$ times better, and the life of the cutter can be extended by $200 \%$ to $300 \%$ if the removal temperature of materials is increased from the room temperature to $360^{\circ} \mathrm{C}$.

Leshock et al. [5] developed a plasma heating-assisted system for lathe machines. First, the plasma heating was generated by the surface temperature through the numerical simulation and an infrared radiation thermometer. The results of numerical simulation and experiment were consistent. Then, the simulation analysis showed all operating parameters which influenced the surface temperature. Finally, the operating conditions of plasma-assisted machining were corrected in accordance with the experimental results. Compared to traditional machining, the plasmaassisted machining can reduce the cutting force by $30 \%$ and extend the lifetime of the cutter by about $40 \%$.

Hyndman et al. [6] expanded the exponential smoothing application to automatic operation prediction. It has been proven that each exponential smoothing method can provide prediction which is consistent with the results of the state-space model.

Paul [7] indicated that exponential smoothing is one of the essential quantization technologies for prediction. Since the accuracy of prediction depends on the exponential smoothing constant, an appropriate constant is critical for error reduction in prediction. In the research, the optimum value of exponential smoothing was selected based on MSE and MAD, and it will be verified by the trial-and-error method.

The cutting of nickel-based materials is very difficult due to short tool life and severe surface abuse of the machined surface. The key strengthening of superalloys are austenitic base solid solution strengthening, precipitation strengthening, and grain boundary strengthening [8-12]. Nickelbased alloys have low thermal conductivity, machining hardness, and the affinity between the tool and the chip to cause rapid tool wear $[13,14]$.

\section{Theoretical Analysis and Introduction}

2.1. Plasma Heating Theory. Plasma heating is the method for workpiece heating and melting by ejecting the superheated and high-speed gas stream electrolyzed through the electric arc discharge under normal atmosphere. Plasma, called the 4th state of matter, is composed of positively charged ions and negatively charged free electrons which are electrolyzed from gas atoms or molecules. Because the overall positive and negative electric charges to equal of the gas, so called plasma.

The extremely high energy density of the plasma-assisted machining tool is caused by the following effects:

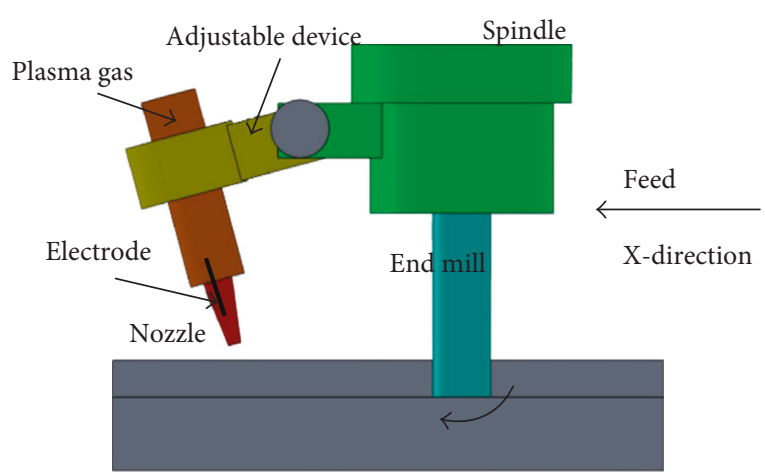

FIGURE 1: Plasma heat source movement in the feed direction at the feed velocity.

(1) Mechanical compression effect: to increase the energy density and temperature of the arc column by the nozzle diameter

(2) Thermal compression effect: to enhance the current density and temperature again by injecting cooling water into the nozzle to reduce the temperature of the nozzle inner wall

(3) Magnetic contraction effect: to reduce the cross section area of the arc and to increase the current density for arc stability since the arc current can be deemed as infinite current lines in the same direction, and each current line is attractive to all the others

Based on the effects, the cross section area of the plasma arc will be reduced so that the energy of the plasma arc will be concentrated to increase the density to $105-106 \mathrm{~W} / \mathrm{cm}^{2}$ and temperature to $10,000-20,000^{\circ} \mathrm{C}$. Thus, the plasma gas, ejecting at a speed of 104-107 m/s, will create a huge impact force. When the plasma gas reaches the surface of the workpiece, a lot of heat will be released to heat the workpiece with an extremely high temperature [15].

2.2. Heat Conduction in Plasma-Assisted Machining. Temperature is the key in the machining process. Workpieces will be heated with different temperatures in accordance with the types of heat transfer and the physical properties of the workpiece. The 3 types of heat transfer, heat conduction, heat convection, and heat radiation, can operate alone or simultaneously $[7,16]$. Figure 1 shows the plasma heat source movement in the feed direction at the feed velocity, $F$. The plasma heat source will heat the cutting surface regularly and cause the thermal superposition effect. Assuming that the heat is uniform, the transient state of the machining process is analyzed. The power can be shown as the following expression $[17,18]$ :

$$
Q=0.24 \times I \times V \times \eta
$$

where $I$ is the current of plasma-assisted machining, $V$ is the voltage of plasma-assisted machining, and $\eta$ is the thermal efficiency of plasma-assisted machining. 


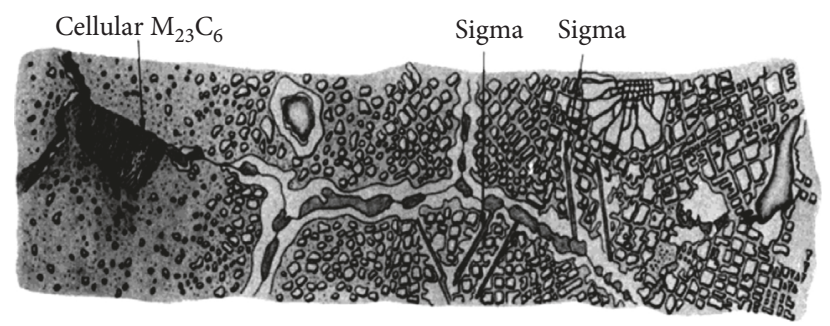

(a)

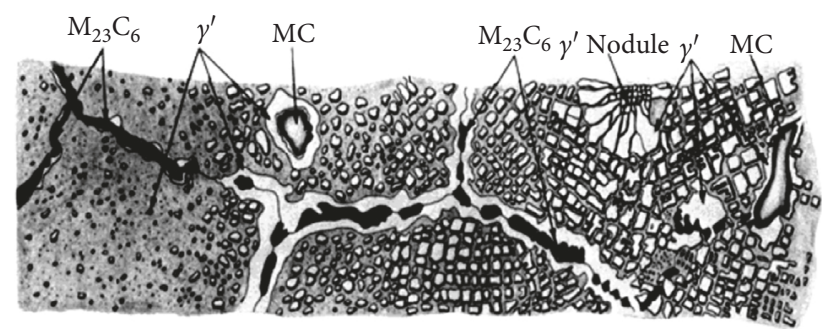

(b)

FIgURE 2: Coherency strain generated by precipitates and the base [18].

The feed speed of the high-speed CNC machine tool is in direct proportion to the spindle speed, the number of flutes, and the feed rate per flute. The feed speed in the experiment in the research is shown as the following expression:

$$
F=F_{t} \times Z \times N \mathrm{~mm} / \mathrm{min},
$$

where $F_{t}$ is the feed rate per flute, $Z$ is the number of flutes, and $N$ is the spindle speed.

The relationship between machining speed and heat is shown as the following expression [19]:

$$
Q=\frac{V \times I}{S} \times 60 \text {. }
$$

2.3. Material Characteristics of Inconel-718. The strengthening mechanism for nickel base superalloy can be divided into (1) austenitic base solid-solution strengthening; (2) precipitation strengthening for $\gamma^{\prime}$ and $\gamma^{\prime \prime}$; and (3) grain boundary strengthening [8-12].

(1) Austenitic base solid-solution strengthening: Inconel718 alloy contains about $19 \%$ of $\mathrm{Cr}$ and 3\% of Mo. Since the atomic volumes of $\mathrm{Cr}$ and Mo are both larger than those of $\mathrm{Ni}$, the substitutional solid solution will be formed when it is solubilized in the base. Thus, the grain lattice of the base will be distorted and the strain will be generated for strengthening.

(2) Precipitation strengthening for $\gamma^{\prime}$ and $\gamma^{\prime \prime}$ : both of $\gamma^{\prime}$ and $\gamma^{\prime \prime}$ are regular and coherent precipitates. Generally, their strengthening effect is caused by

(a) the reversed phase boundary and defect hardening when the dislocation generates precipitates;

(b) coherency strain as shown in Figure 2;

(c) the climb or by-passing forced by dislocation to form the dislocation loop of precipitates when the volume of precipitates is large enough; (d) the size or the volume percent of precipitates.

(3) Grain boundary strengthening: the effect is generated by the precipitation of carbide to block the grain boundary sliding. A small amount of B (boron) is segregated to the grain boundary to reduce the diffusion. Moreover, the grain size and direction can be controlled to enhance the strengthening effect and the mechanical properties.

2.4. Machining Characteristics of Inconel-718. In the modern cutting history, nickel base superalloy is categorized to a kind of difficult-to-machine materials. The major reasons are listed in the subsequent sections [20, 21].

2.4.1. Large Work Hardening. Since $\gamma^{\prime}$ and $\gamma^{\prime \prime}$ phases are both FCC, their mechanical properties are better ductility, and the difference between their lattice constants is about $1 \%$. Through the coherent precipitation strengthening effect of the $\gamma^{\prime}$ phase, the strengthening mechanism for nickel base superalloy keeps high mechanical strength, as shown in Figure 3 and Table 1. Since it coheres to the base well under conditions of the precipitation strengthening of $\gamma^{\prime}$ and $\gamma^{\prime \prime}$ in high temperature $\left(650^{\circ} \mathrm{C}\right)$, the flow stress is still high even through plastic deformation is higher. During the cutting process, there are extremely high strain rate $\left(\gamma \approx 10^{5}\right)$ and large plastic deformation in the shear zone [17]. A great amount of solid solution, the precipitates of Inconel-718 materials, will block the dislocation movement during the plastic deformation process. However, the coherent precipitation strengthening effect and the amount of solid solution will increase the hightemperature deformation strength of nickel base alloy and easily damage the cutter [22]. 


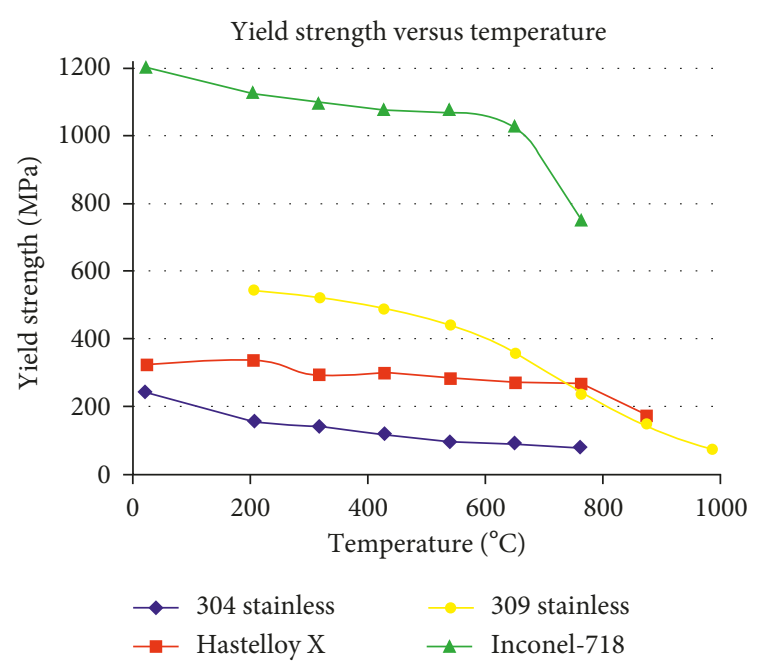

FIGURE 3: Shear strength of Inconel-718 versus temperature [23].

TABLE 1: Inconel-718 different temperature mechanical properties.

\begin{tabular}{lccc}
\hline $\begin{array}{l}\text { Temperature } \\
\left({ }^{\circ} \mathrm{C}\right)\end{array}$ & $\begin{array}{c}\text { Tensile strength } \\
(\mathrm{MPa})\end{array}$ & $\begin{array}{c}\text { Yield strength } \\
(\mathrm{MPa})\end{array}$ & $\begin{array}{c}\text { Elongation } \\
(\%)\end{array}$ \\
\hline 21 & 1430 & 1190 & 21 \\
540 & 1280 & 1060 & 18 \\
650 & 1230 & 1020 & 19 \\
750 & 950 & 740 & 25 \\
870 & 340 & 330 & 88 \\
\hline
\end{tabular}

2.4.2. Low Heat Transfer Rate. The low heat transfer rate of nickel base superalloy is also a major issue related to cutting. In general, most of the heat generated during the cutting process of nickel base superalloy will be transferred to the cutter instead of chips. Moreover, the high yield stress and high tensile strength of nickel base superalloy cause the cutter to withstand the high temperature and high stress. It easily wears the cutter out and may cause tipping [15].

\section{Principles of Exponential Smoothing}

The exponential smoothing forecasting methods use constants that assign weights to the current demand and previous forecasts to arrive at new forecasts. Their values influence the responsiveness of forecasts to the actual demand and hence influence forecast error. Considerable effort has focused on finding the appropriate values to use. One approach is to use smoothing constants that minimize some function of forecast error [24].

Exponential smoothing adopts the full-time moving average method in time series for applications and predictions. The linear trend of time series can be analyzed and predicted by the first exponential smoothing. Moreover, the second curved trend of time series can be operated by the third exponential smoothing. The principles of the second exponential smoothing are similar to those of the third one. The expressions of the three exponential smoothing are listed as follows [25]:

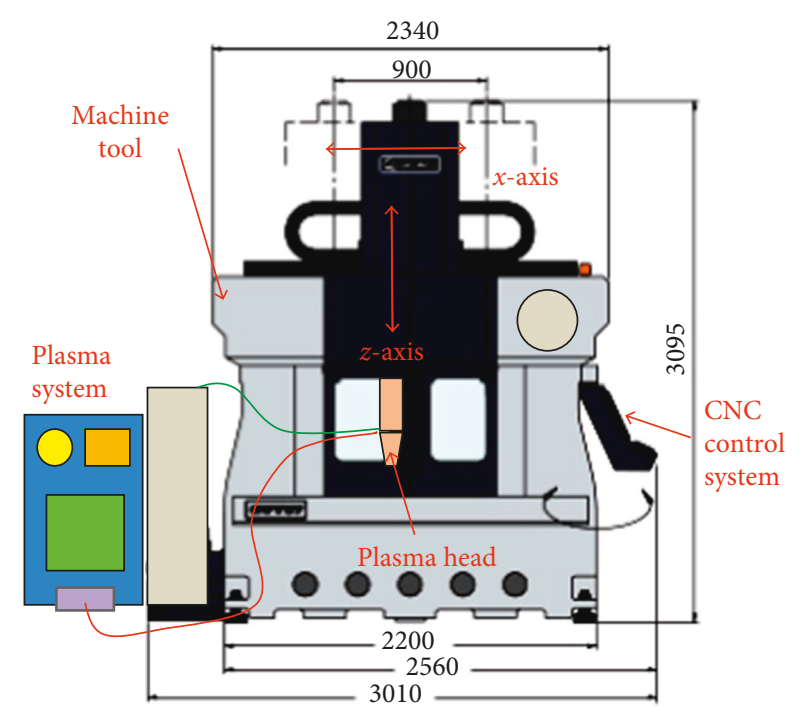

FIgURE 4: Integration of the CNC machine tool and the plasma device.

$$
\begin{aligned}
& S_{t}^{(1)}=\alpha Y_{t}+(1-\alpha) S_{t-1}^{(1)}, \\
& S_{t}^{(2)}=\alpha S_{t}^{(1)}+(1-\alpha) S_{t-1}^{(2)}, \\
& S_{t}^{(3)}=\alpha S_{t}^{(2)}+(1-\alpha) S_{t-1}^{(3)},
\end{aligned}
$$

where $S_{t}$ is the exponential smoothing value of time $t, Y_{t}$ is the exponential actual value of time $t, S_{t-1}$ is the exponential smoothing value of time $t-1, \alpha$ is the smoothing constant in $[0,1]$, and $S_{t}^{3}$ is the three exponential smoothing value of time $t$.

The trend prediction in exponential smoothing is the predicted value plus correction value. The prediction model of the three exponential smoothing is listed as follows:

$$
\text { Temp }_{t+T}=a_{t}+b_{t} T+c_{t} T^{2}
$$

where $a_{t}, b_{t}$, and $c_{t}$ are the undetermined coefficients of exponential smoothing. Through curve fitting, they can be shown as follows:

$$
\begin{aligned}
& a_{t}=3\left(S_{t}^{(1)}-S_{t}^{(2)}\right)+S_{t}^{(3)}, \\
& b_{t}=\frac{\alpha}{2(1-\alpha)^{2}}\left[(6-5 \alpha) S_{t}^{(1)}-2(5-4 \alpha) S_{t}^{(2)}+(4-3 \alpha) S_{t}^{(3)}\right], \\
& c_{t}=\frac{\alpha}{2(1-\alpha)^{2}}\left(S_{t}^{(1)}-2 S_{t}^{(2)}+S_{t}^{(3)}\right) .
\end{aligned}
$$

\section{Experimental Device and Method}

4.1. Experimental Device. The research adopted a triaxial gantry high-speed machine tool in the experiment as shown in Figure 4. Since the workbench was fixed, the 3 axes, $x, y$, and $z$, moved on the crossbeam by travelling $1000 \mathrm{~mm}, 800 \mathrm{~mm}$, and $700 \mathrm{~mm}$, respectively. The feed velocity was from 1 to $20,000 \mathrm{~mm} / \mathrm{min}$, and the maximum revolution of the main 


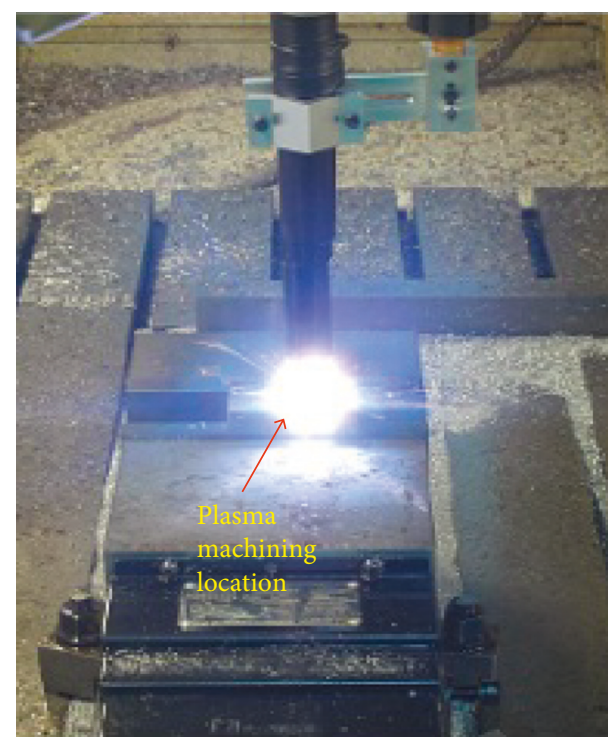

FIGURE 5: Experimental device shooting.

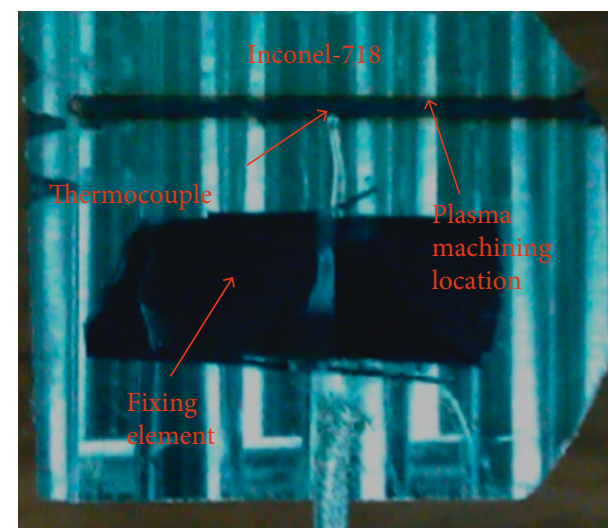

Figure 6: Measuring device and the test method.

spindle was 14,000 rpm. The maximum power was $25 \mathrm{KW}$. In addition, the variable-frequency DC plasma electrode machining head was installed on the main spindle of the CNC machine tool. The pulse current was continuously varying from 5 to $150 \mathrm{~A}$. The input voltage was three-phase AC $220 \mathrm{~V} \pm 10 \% / 60 \mathrm{~Hz}$, and the pulse frequency was divided into none, low frequency $(0.5 \sim 25 \mathrm{~Hz})$, and intermediate frequency $(10 \sim 100 \mathrm{~Hz})$. Moreover, the current rise time and fall time were $0.1-5 \mathrm{sec}$ and $0.2-10 \mathrm{sec}$, respectively. The current and voltage to guide the electric arc were $3-30 \mathrm{~A}$ and $\mathrm{DC} 15 \mathrm{~V}-17 \mathrm{~V}$. Finally, the experiment adopted the K-type thermocouple sensing device to measure the temperature from -200 to $1370^{\circ} \mathrm{C}$. The resolution is from -200 to $200^{\circ} \mathrm{C}$ with the error of $0.1^{\circ} \mathrm{C}$, and the sampling rate was 2.5 times per second.

4.2. Experimental Method. The research aimed to explore the temperature distribution of heated nickel base superalloy and to compare the results with those of medium carbon steel. The independent variables were the plasma current $I(20$, $40,60$, and $80 \mathrm{~A})$ and the feed velocity $F(1,000,2,000$, and

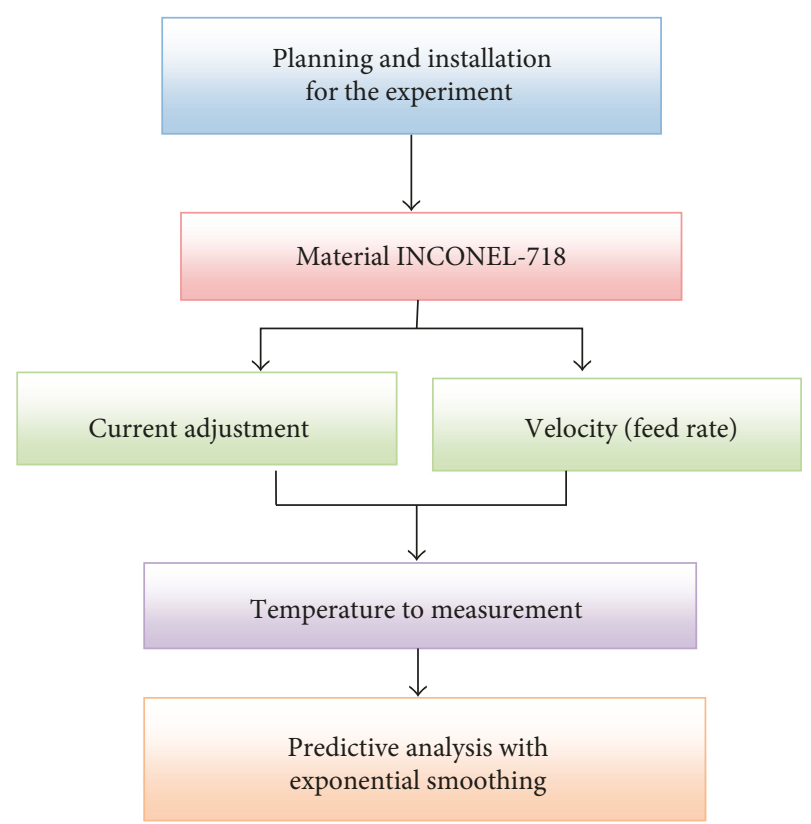

Figure 7: Experiment flow chart.

$3,000 \mathrm{~mm} / \mathrm{min}$ ). In addition, the thermocouple sense lines were installed on the material surface with $2 \mathrm{~mm}$ distance from the center of the weld for not being burned out by the extremely high temperature of the weld electric arc. Figure 5 shows experimental device shooting, Figure 6 shows the measuring method, and Figure 7 shows the experiment flow chart. The main application of this study experiments and predictions, the control factor for the current value and feed rate. Temperature is the target of measurement and prediction. The predicted value is the reference value of the depth of cut.

\section{Results and Discussion}

5.1. Measurement of Inconel-718 Temperature Distribution. The impacts of current and feed velocity on temperature are discussed in this section. The temperature was measured through the thermocouples installed in the workpiece. Figures 8 and 9 show the relationship between temperature and time under conditions of the feed velocity of 1,000 and $3,000 \mathrm{~mm} / \mathrm{min}$, respectively. If the current is larger, the temperature is higher. As the expression (1), when the voltage and current are increased, the heat source power will be increased and then the temperature will be increased rapidly. In addition, if the feed velocity is faster, the temperature will be lower since the faster feed velocity causes less heating duration per unit area.

5.2. Temperature Prediction Based on Exponential Smoothing. In the second section, exponential smoothing was applied to predict the variations of the highest temperatures and actual values. In the experiment, the variation and error were measured under conditions of the fixed feed velocity and variable smoothing constant. Moreover, the experiment adopted the first and three exponential smoothing methods 


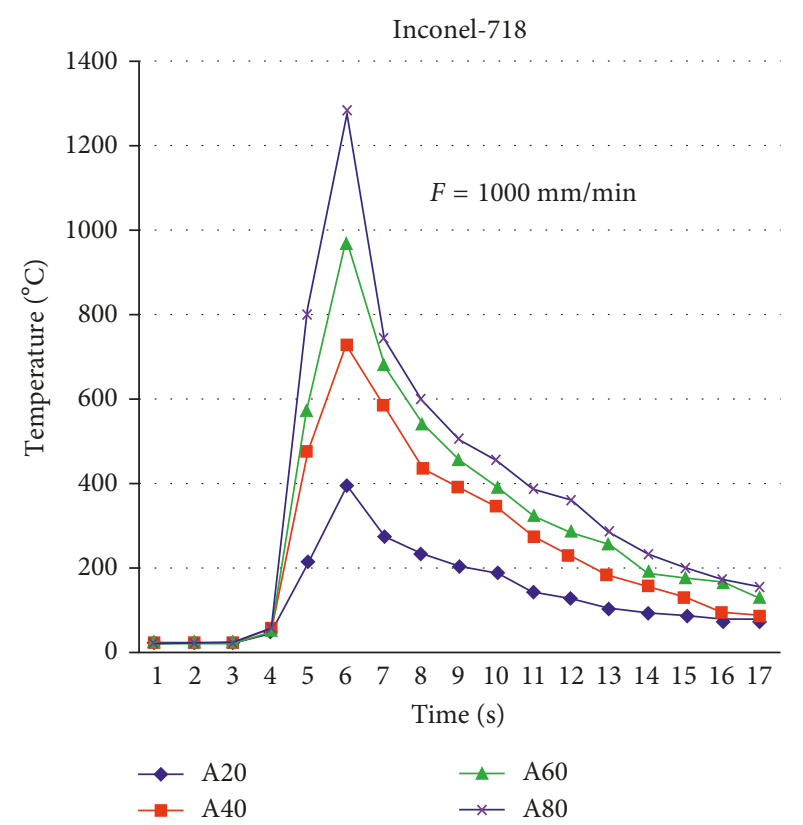

Figure 8: Relationship between temperature and time $(F=1,000 \mathrm{~mm} / \mathrm{min})$.

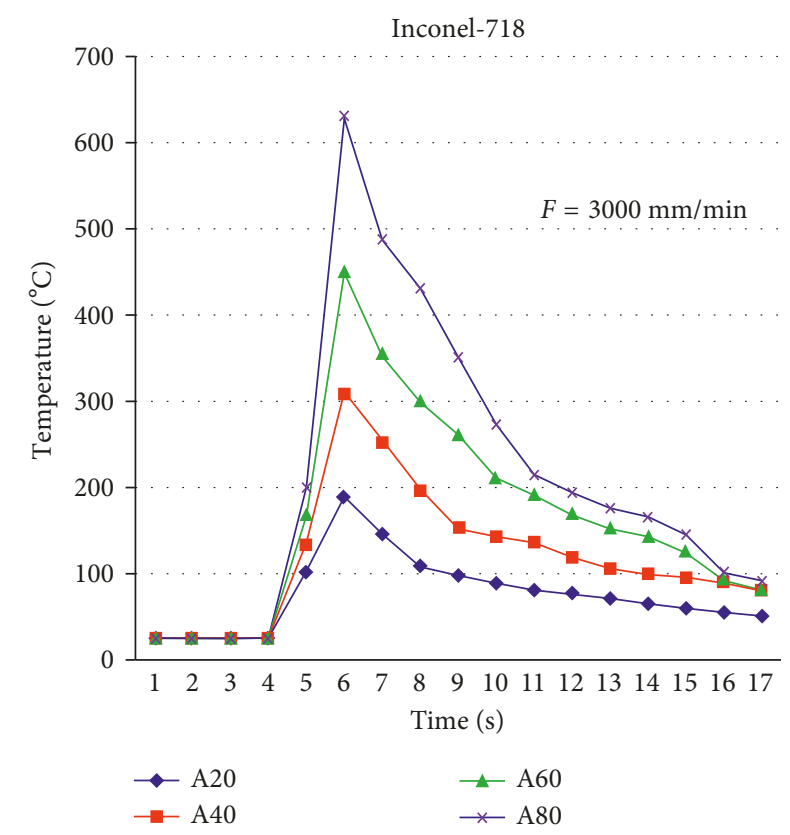

Figure 9: Relationship between temperature and time $(F=3,000 \mathrm{~mm} / \mathrm{min})$.

for prediction. Input the $80 \mathrm{~A}$ current, $1,000 \mathrm{~mm} / \mathrm{min}$ feed velocity, and smoothing constant for $a=0.5$, the experimental results are shown in Figure 10. The temperature increased instantly in the period from 5 to 6 seconds. Although the prediction of the first exponential smoothing was more close to the experimental trend, the error was significant as shown in Figure 11.

When applying a larger smoothing constant, such as $\alpha=0.8$, the prediction of the first exponential smoothing

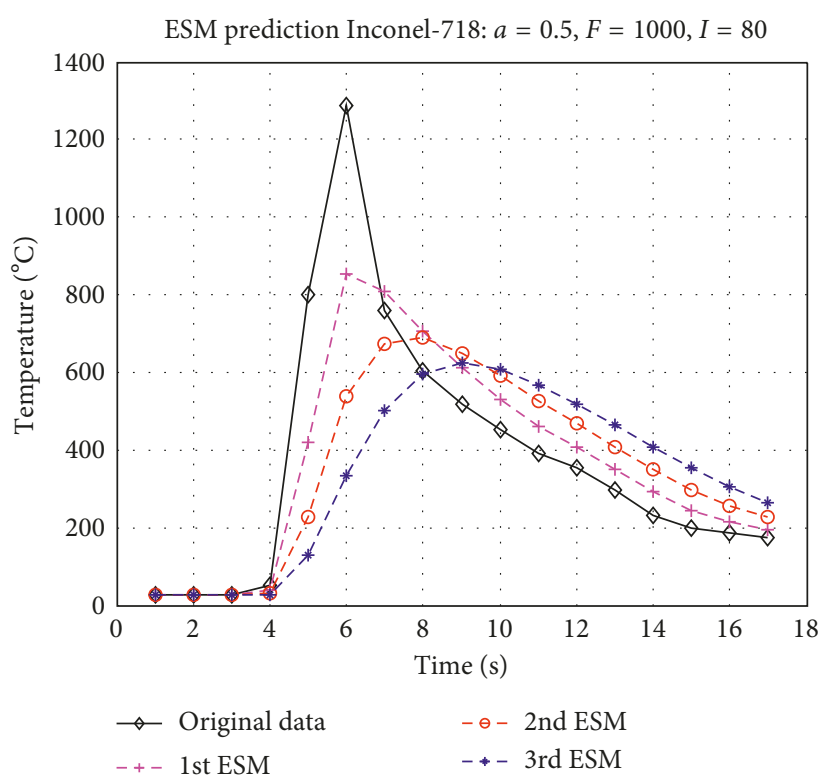

FIgUre 10: Predictive analysis of temperature and time $(F=1,000 \mathrm{~mm} / \mathrm{min}$ and $\alpha=0.5)$.

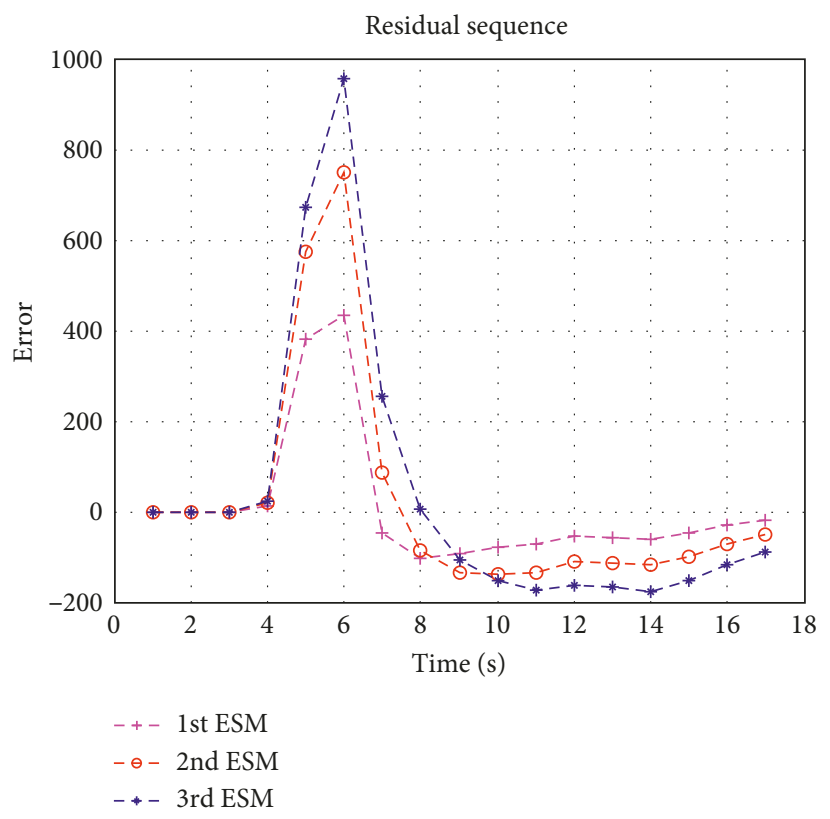

FIgURE 11: Error analysis of temperature and time $(F=1,000 \mathrm{~mm} / \mathrm{min}$ and $\alpha=0.5)$.

was more close to the experimental trend than that of the three exponential smoothing as shown in Figure 12 . According to the analysis of mean absolute percentage error (MAPE) in Table 2 and as shown in Figure 13, the errors of second and three exponential smoothing methods were both more than those of the single one. Compared with the first exponential smoothing, the trend of the second exponential smoothing was more close to linear equation. Also, the error was larger because of accumulation. 


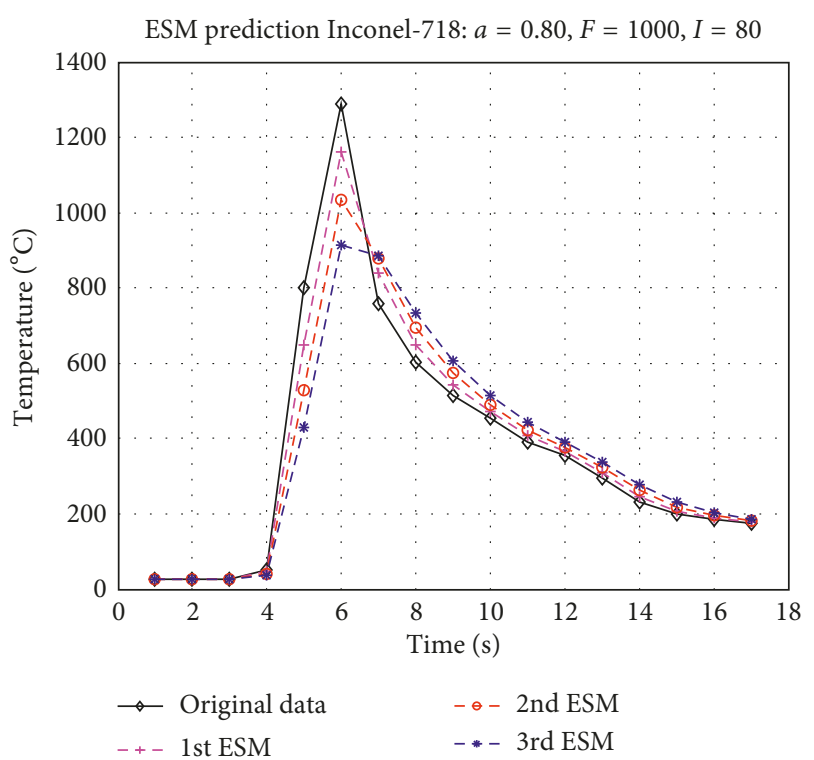

Figure 12: Predictive analysis of temperature and time $(F=1,000 \mathrm{~mm} / \mathrm{min}$ and $\alpha=0.8)$.

TABLe 2: Analysis of mean absolute percentage error (MAPE).

\begin{tabular}{lcccc}
\hline & \multicolumn{2}{c}{$F=1000, I=80 \mathrm{~A}$} & \multicolumn{2}{c}{$F=3000, I=80 \mathrm{~A}$} \\
& $\alpha=0.5$ & $\alpha=0.8$ & $\alpha=0.5$ & $\alpha=0.8$ \\
\hline 1st ESM & 1.16 & 0.17 & 1.21 & 0.22 \\
2nd ESM & 2.95 & 0.37 & 2.63 & 0.50 \\
3rd ESM & 5.25 & 0.61 & 4.15 & 0.82 \\
\hline
\end{tabular}

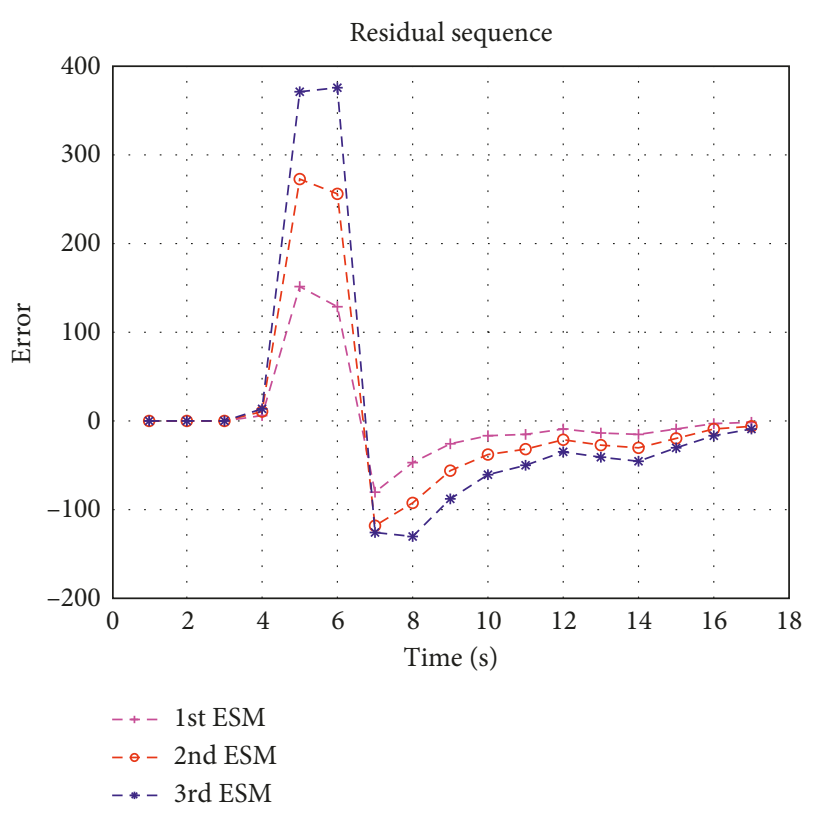

FIgURE 13: Error analysis of temperature and time $(F=1,000 \mathrm{~mm} / \mathrm{min}$ and $\alpha=0.8)$.

When the feed velocity was increased to $3,000 \mathrm{~mm} / \mathrm{min}$, the highest temperature became $628^{\circ} \mathrm{C}$, which was significantly lower than the temperature of $1,000 \mathrm{~mm} / \mathrm{min}$ feed

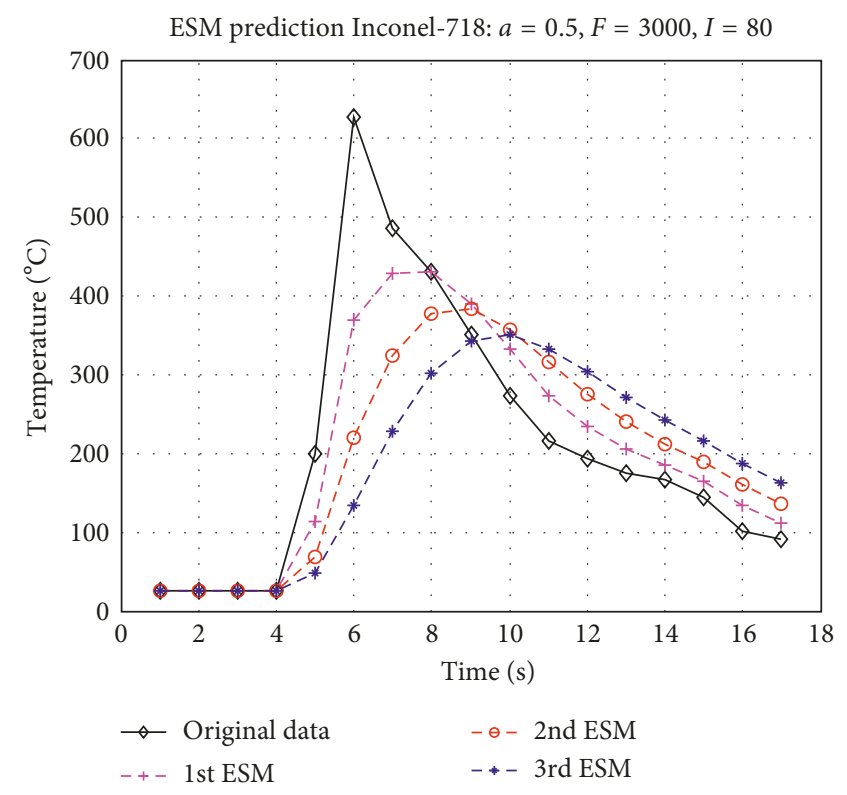

Figure 14: Predictive analysis of temperature and time $(F=3,000 \mathrm{~mm} / \mathrm{min}$ and $\alpha=0.5)$.

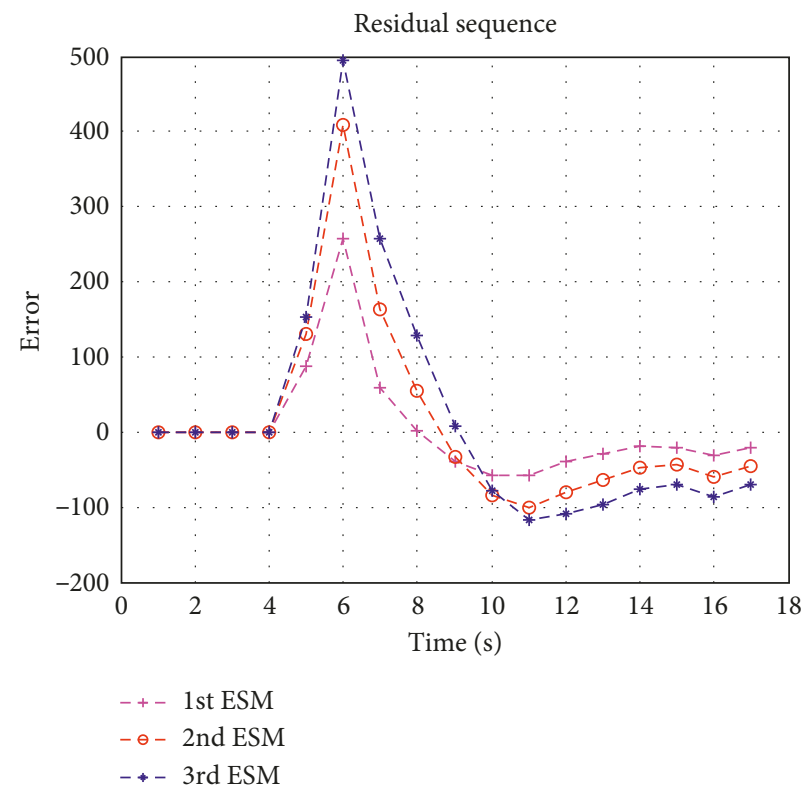

Figure 15: Error analysis of temperature and time $(F=3,000 \mathrm{~mm} / \mathrm{min}$ and $\alpha=0.5)$.

velocity. It was because the heat source was inversely proportional to the velocity and the still duration of the transient state at the point. The smoothing constant $a=0.5$, and the prediction is shown in Figure 14. Compared to the predictions of the first exponential smoothing, the errors at $3,000 \mathrm{~mm} / \mathrm{min}$ feed velocity were larger than those at $1,000 \mathrm{~mm} / \mathrm{min}$, as shown in Figure 15. On the contrary, the errors of the three exponential smoothing at $1,000 \mathrm{~mm} / \mathrm{min}$ feed velocity were more than those at $3,000 \mathrm{~mm} / \mathrm{min}$. Since the instant temperature variation was larger obviously at 


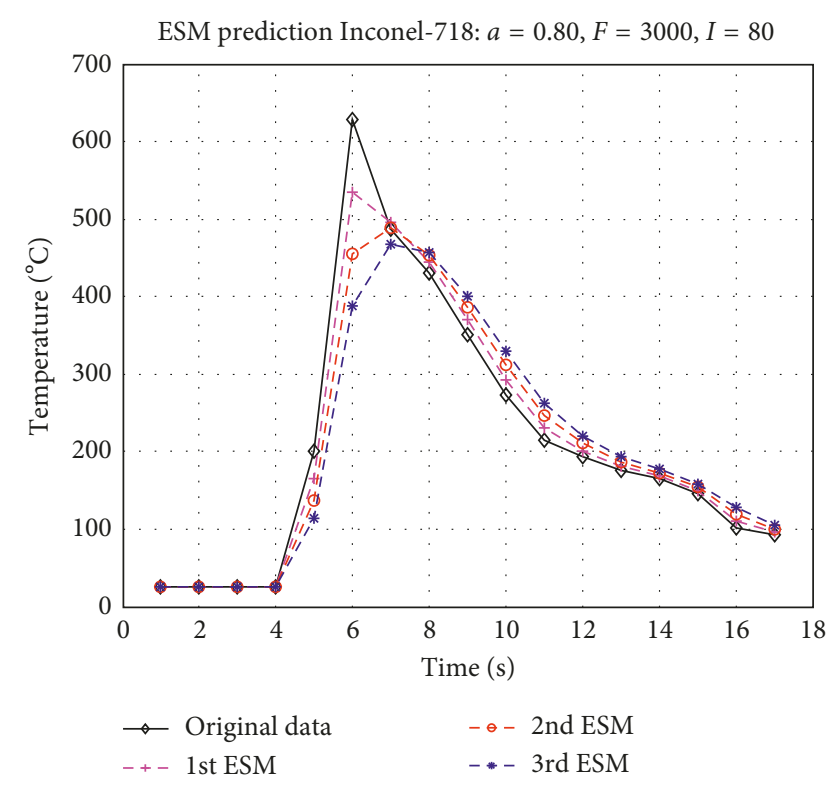

FIgUre 16: Predictive analysis of temperature and time $(F=3,000 \mathrm{~mm} / \mathrm{min}$ and $\alpha=0.8)$.

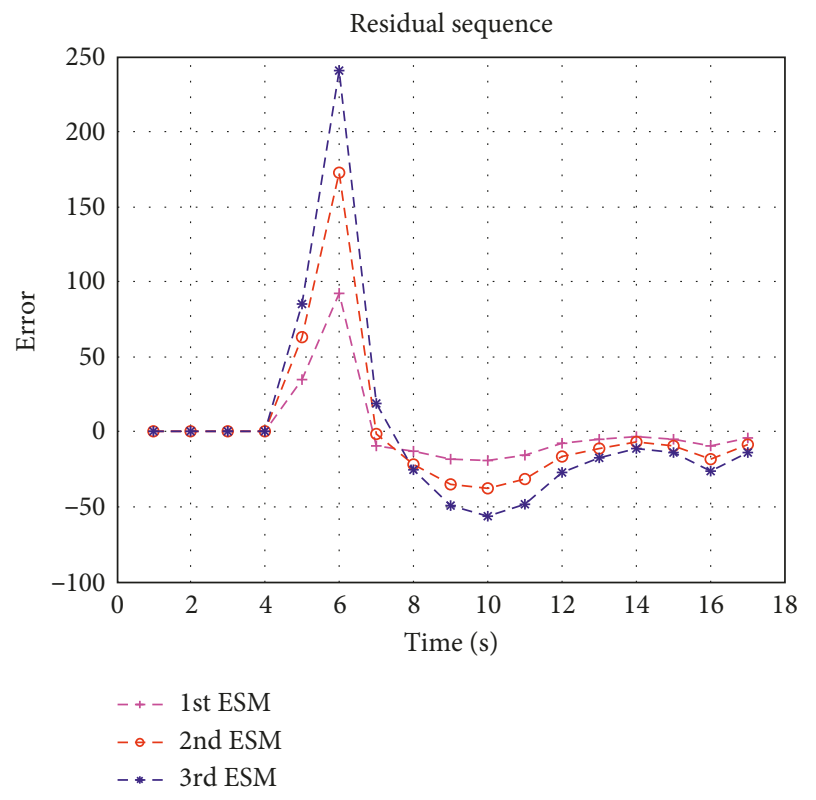

Figure 17: Error analysis of temperature and time $(F=3,000 \mathrm{~mm} / \mathrm{min}$ and $\alpha=0.8)$.

TABle 3: Exponential smoothing prediction model.

\begin{tabular}{lc}
\hline Machining & Prediction model \\
\hline$F=1000, I=80 \mathrm{~A}, a=0.5$ & Temp. $=1267+584.1 T+536.9 T^{2}$ \\
$F=1000, I=80 \mathrm{~A}, a=0.8$ & Temp. $=1293+598.8 T+46.1 T^{2}$ \\
$F=3000, I=80 \mathrm{~A}, a=0.5$ & Temp. $=585.42+311.7 T+32.2 T^{2}$ \\
$F=3000, I=80 \mathrm{~A}, a=0.8$ & Temp. $=626.53+501.9 T+91.6 T^{2}$ \\
\hline
\end{tabular}

$F$ : feed rate $(\mathrm{mm} / \mathrm{min})$; I: electric current $(\mathrm{A})$; Temp.: temperature $\left({ }^{\circ} \mathrm{C}\right) ; \mathrm{T}$ : time (sec).
$1,000 \mathrm{~mm} / \mathrm{min}$ feed velocity, the accumulated errors of the three exponential smoothing became larger. However, at $3,000 \mathrm{~mm} / \mathrm{min}$ feed rate, the instant temperature variation was less, and then, the accumulated errors of the three exponential smoothing were less than those at $1,000 \mathrm{~mm} / \mathrm{min}$.

Applying the larger smoothing constant $a=0.8$, in prediction, the trend of the single exponential smoothing was more significantly close to the experiment results than that of the three exponential smoothing as in Figure 16. In addition, the errors at $a=0.8$ smoothing constant were less than those at $a=0.5$. According to Table 2 and as shown in Figure 17, under conditions of $a=0.5$ smoothing constant, the mean absolute percentage errors of second and three exponential smoothing methods at $3,000 \mathrm{~mm} / \mathrm{min}$ feed rate were less than those at $1,000 \mathrm{~mm} / \mathrm{min}$.

5.3. Establishment of the Exponential Smoothing Model. Based on the thermal diffusion formula, the thermal conductivity coefficient is directly proportional to the thermal diffusion. Therefore, the low thermal conductivity coefficient of Inconel-718 leads to low thermal diffusion. The exponential smoothing prediction model is built with 2 stages: the rise stage for heating and the fall stage for thermal diffusion. The research aimed at predicting the temperature variation at the highest temperature through the transient state of the heating process. The temperature prediction model of the machining process is proposed and is shown in Table 3. The cutting temperature in superalloy depends on feed-rate and current and can be estimated using a prediction model.

\section{Conclusion}

Since the material of Inconel-718 easily becomes hard and precipitates the second hardening phase, $\gamma^{\prime \prime}$, in higher temperature, it is difficult to be cut or machined. If the temperature is higher than the critical points $\left(750-850^{\circ} \mathrm{C}\right)$, then the material of Inconcel-718 will become easy for cutting. However, the high temperature may soften the cutter and cause impact on the cutting process. In addition, the cutter should not operate at a speed which is too fast. Therefore, the material of Inconcel-718 can be softened by plasma heating first to smoothen the cutting process. In the experiment, appropriate current and feed parameters should be adopted for preheating since lower temperature may cause few assistance and higher temperature may damage the cutter in a short period of time.

With the increasing current, the temperature is increased significantly since current is an essential factor to heat plasma. A higher feed velocity also leads to a shorter transient state period at one point. Therefore, for the cutting and machining processes, lower feed velocity and higher current will lead to higher temperature at the cutting temperature point. The errors of the three exponential smoothing at $1,000 \mathrm{~mm} / \mathrm{min}$ feed velocity were more than those at $3,000 \mathrm{~mm} / \mathrm{min}$. 
The error of the trend prediction will be less if the smoothing constant $\alpha$ is higher. Moreover, compared to the three exponential smoothing, the trend of the single exponential smoothing is more close to the experimental values. The larger errors of the three exponential smoothing are caused by accumulation, and plasma-assisted machining of nickel-based materials reduces cutting forces and increases tool life. Therefore, the temperature prediction is very important. The exponential smoothing method can correctly predict the temperature. The constant $a=0.8$ is small and the best.

\section{Conflicts of Interest}

The authors declare that they have no conflicts of interest.

\section{References}

[1] D.-X. Du, The Study of Processing Characteristics of Laser Assisted Machining Applied to the SKD-11 Molding Tool Steel Material, Department of Mechanical Engineering, National Chung Cheng University, Chiayi, Taiwan, 2006.

[2] Y. C. Shin, L. Shuting, F. E. Pfefferkorn, P. Rebro, J. C. Rozzi, and F. P. Incropera, Thermally (Laser and Plasma) Assisted Machining: Its Potential and Future, Abrasives Magazine Inc., Byron center, MI, USA, pp.16-23, 2000.

[3] A. Lamikiz and A. Celaya, "Plasma assisted milling of heatresistant super-alloys," Journal of Manufacturing Science and Engineering, vol. 126, p. 274, 2004.

[4] M. Anderson, R. Patwa, and Y. C. Shin, "Laser-assisted machining of Inconel 718 with an economic analysis," International Journal of Machine Tools \& Manufacture, vol. 46, no. 14, pp. 1879-1891, 2006.

[5] C. E. Leshock, J.-N. Kim, and Y. C. Shin, "Plasma enhanced machining of Inconel 718: modeling of workpiece temperature with plasma heating and experimental results," International Journal of Machine Tools \& Manufacture, vol. 41, no. 6, pp. 877-897, 2001.

[6] R. J. Hyndman, A. B. Koehler, R. D. Snyder, and S. Grose, “A state space framework for automatic forecasting using exponential smoothing methods," International Journal of Forecasting, vol. 18, no. 3, pp. 439-454, 2002.

[7] S. K. Paul, "Determination of exponential smoothing constant to minimize mean square error and mean absolute deviation," Global Journal of Research in Engineering, vol. 11, no. 3, 2011.

[8] Z. Y. Wang, K. P. Rajurkar, J. Fan, S. Lei, Y. C. Shin, and G. Petrescu, "Hybrid machining of Inconel 718," International Journal of Machine Tools \& Manufacture, vol. 43, no. 13, pp. 1391-1396, 2003.

[9] M. Rahman, W. K. H. Seah, and T. T. Teo, "Machinability of Inconel-718," Journal of Material Processing Technology, vol. 63, pp. 199-204, 1997.

[10] G. Germain, P. Dal Santo, and J. L. Lebrun, "Comprehension of chip formation in laser assisted machining," International Journal of Machine Tools and Manufacture, vol. 54, no. 3, pp. 230-238, 2011.

[11] R. Muhammad, "Thermally enhanced ultrasonically assisted machining of Ti alloy," CIRP Journal of Manufacturing Science and Technology, vol. 7, no. 2, pp. 159-167, 2014.

[12] D. G. Thakur, B. Ramamoorthy, and L. Vijayaraghavan, "Machinability investigation of Inconel 718 in high-speed turning," International Journal of Advanced Manufacturing Technology, vol. 45, no. 5-6, pp. 421-429, 2009.
[13] M. C. Shaw, Metal Cutting Principles, Oxford University Press, Oxford, UK, 1984.

[14] C. T. Sim, N. S. Stoloff, and W. C. Hangel, Super-Alloys, A Wiley- Interscience Publication, 1987.

[15] X. K. Ming, Non-Traditional Processing, Quanhua Publishing House, Nanjing, China, 1978, in Chinese.

[16] S. Skvarenina and Y. C. Shin, "Laser-assisted machining of compacted graphite iron," International Journal of Machine Tools \& Manufacture, vol. 46, no. 1, pp. 7-17, 2006.

[17] W. Zhongyin, D. Liguang, and X. Faren, "Study of heat conduction mathematic model of plasma hot machining," Journal of Guangxi Institute of Technology, vol. 5, no. 4, pp. 45-50, 1994.

[18] H.-Y. Bor, A Study on the Elevated Temperature Brittleness and Fracture Mechanism of Mar-M247 Super-Alloy, National Chiao Tung University, Hsinchu, Taiwan, 1998.

[19] Welding Laboratory, Shenyang Mechanical and Electrical Engineering Institute, China Science Press, Beijing, China, 1978.

[20] S.-H. Chen, "Study on application of grey prediction model in super-alloy MAR-247 machining," Advances in Materials Science and Engineering, vol. 2015, Article ID 704143, 10 pages, 2015.

[21] H. G. Chun, T. Y. Cho, J. H. Yoon, and G. H. Lee, "Improvement of surface properties of Inconel718 by HVOF coating with WC-metal powder and by laser heat treatment of the coating," Advances in Materials Science and Engineering, vol. 2015, Article ID 468120, 7 pages, 2015.

[22] M. Alauddin, M. A. El Baradie, and M. S. J. Hashmi, "Endmilling machinability of Inconel-718," Journal of Engineering Manufacture, vol. 210, no. 1, pp. 11-22, 1996.

[23] H. V. Ravinder, "Forecasting with exponential smoothingwhat's the right smoothing constant," Review of Business Information Systems-Third Quarter, vol. 17, no. 3, p. 117, 2013.

[24] S. J. Shaffer, Hardness Testing at Elevated Temperatures, Bruker TMT, Cherry Hill, NJ, USA, 2014.

[25] J. W. Taylor, "Exponential smoothing with a damped multiplicative trend," International Journal of Forecasting, vol. 19, no. 4, pp. 715-725, 2003. 


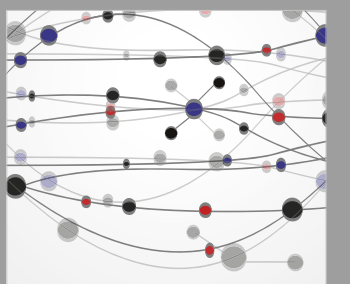

The Scientific World Journal
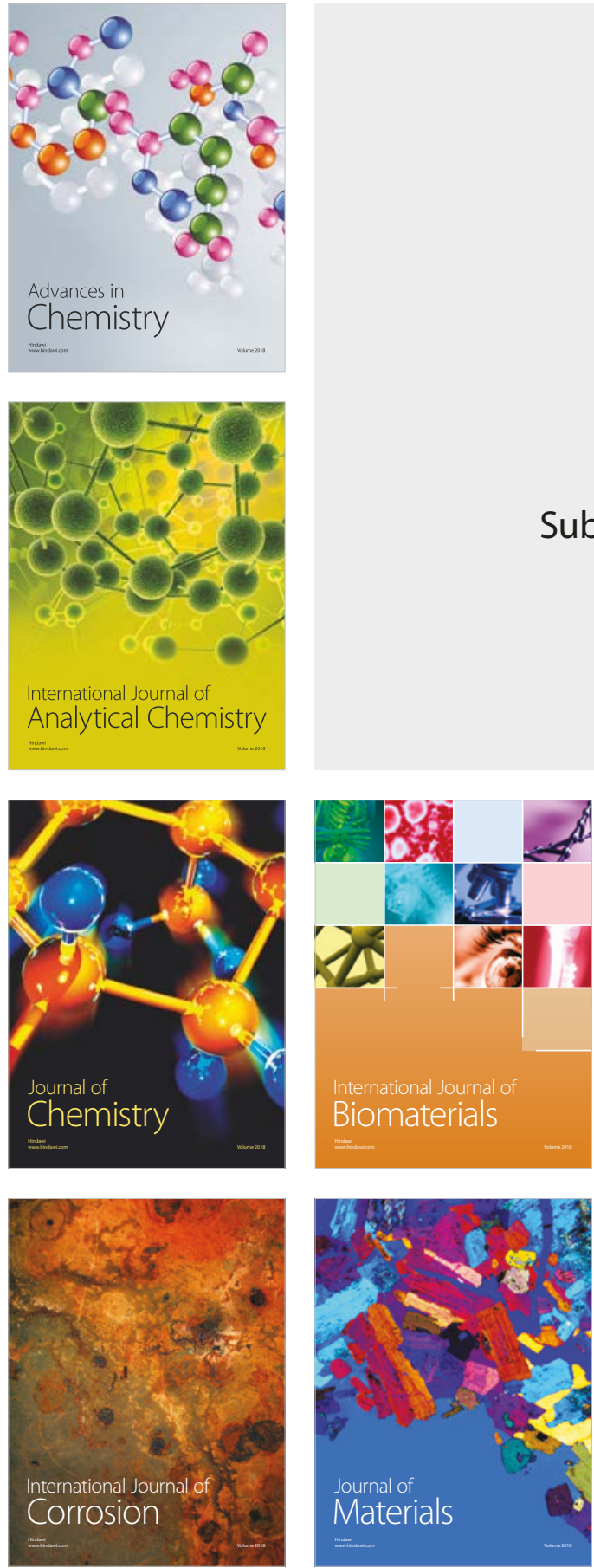

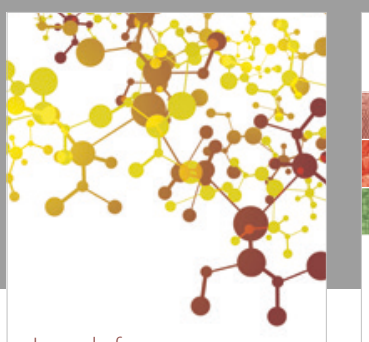

Journal of

Applied Chemistry
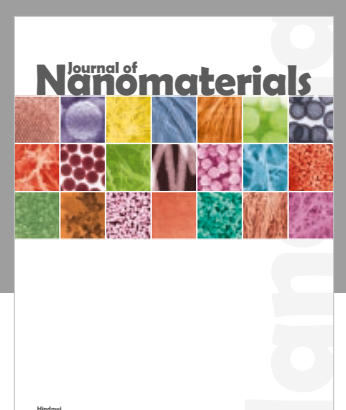

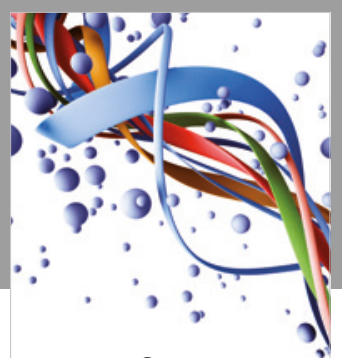

Scientifica

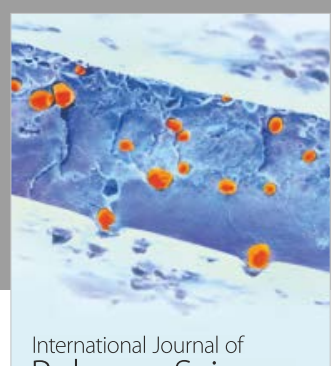

Polymer Science

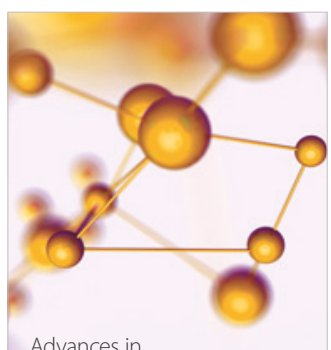

Physical Chemistry
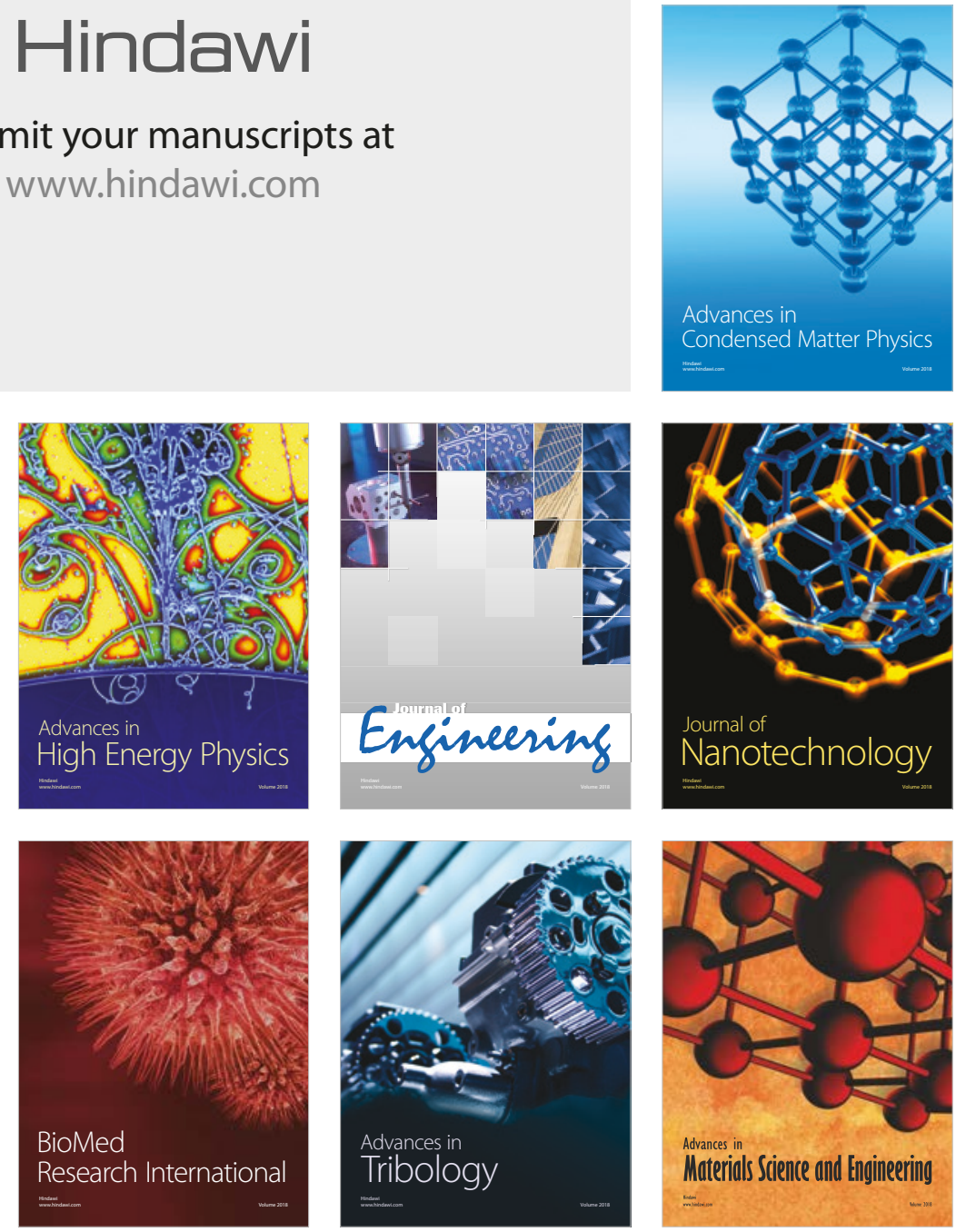